\title{
Effects of salinomycin and CGP37157 on head and neck squamous cell carcinoma cell lines in vitro
}

\author{
AGMAL SCHERZED, STEPHAN HACKENBERG, KATRIN FROELICH, KRISTEN RAK, CHRISTIAN GINZKEY, \\ RUDOLF HAGEN, PHILIPP SCHENDZIELORZ and NORBERT KLEINSASSER
}

\begin{abstract}
Department of Oto-Rhino-Laryngology, Plastic, Aesthetic and Reconstructive Head and Neck Surgery, Julius-Maximilian-University of Wuerzburg, Wuerzburg D-97080, Germany
\end{abstract}

Received August 15, 2014; Accepted May 13, 2015

DOI: $10.3892 / \mathrm{mmr} .2015 .3981$

\begin{abstract}
Surgery, radiation, chemotherapy or a combinations of these are all accepted modalities for the treatment of head and neck squamous cell carcinoma (HNSCC). Despite this, 40-60\% of patients suffering from HNSCC develop loco-regional failure and/or distant metastases. Salinomycin has been demonstrated to be $>100$-fold more effective than paclitaxel at causing cancer stem cell death, therefore, it may offer an important improvement in cancer therapy. However, the toxicity of salinomycin is of concern. A possible solution may be the administration of additive drugs, which reduce the toxicity. By inhibiting the mitochondrial $\mathrm{Na}^{+} / \mathrm{Ca}^{2+}$ exchanger using the benzodiazepine derivate, CGP37157 (CGP), a significant reduction in salinomycin neuronal toxicity has been observed. This raises the question of whether CGP also inhibits the tumor toxicity of salinomycin. In the present study, the FaDu and HLaC79 C1 HNSCC cell lines were treated with salinomycin with or without CGP. Comparative viability assessments were performed using microscopy, a fluorescein diacetate assay, an MTT assay, a clonogenic assay and annexin V-propidium iodide staining. The expression levels of MDR-1 were monitored using reverse transcription-quantitative polymerase chain reaction. Salinomycin alone, and in combination with CGP, achieved a significant attenuation of cell viability and increased apoptosis in a dose-dependent manner. However, the tumor toxicity of salinomycin was not inhibited by CGP. The HLaC79 C1 cells were more sensitive to salinomycin, compared with the FaDu cells, with this sensitivity being due to high expression levels of MDR-1 by the HLaC79 C1 cells. In conclusion, CGP did not counteract the tumor toxicity of salinomycin in vitro and may be a promising drug in future
\end{abstract}

Correspondence to: Professor Norbert Kleinsasser, Department of Oto-Rhino-Laryngology Plastic, Aesthetic and Reconstructive Head and Neck Surgery, Julius-Maximilian-University of Wuerzburg, 11 Josef-Schneider-Straße, Wuerzburg D-97080, Germany

E-mail: kleinsasser_n@ukw.de

Key words: squamous carcinoma cell line, head and neck squamous cell carcinoma, salinomycin, MDR-1 anticancer therapy. The results of the present study encourages further investigation of the toxicological aspects of salinomycin, particularly in human cells and animal models.

\section{Introduction}

In total, 500,000 new cases of head and neck squamous cell carcinoma (HNSCC) are diagnosed annually worldwide (1). The majority of these patients suffer from locally advanced stage disease (2). The treatment options for head and neck cancer include surgery, radiation, chemotherapy or a combination of these modalities. Unresectable SCC formations of the head and neck are frequently treated with concurrent chemotherapy (3). However, 40-60\% of patients suffering from HNSCC develop loco-regional failure and distant metastases (4). It has been suggested that this cancer treatment failure is due to the presence of a certain subpopulation of cancer cells, termed cancer stem cell-like cells or cancer initiating cells (CSCs) $(5,6)$. Therefore, there is an increasing requirement for more cancer cell-specific drugs. Gupta et al (7) investigated salinomycin as a selective killer of CSCs in a high-throughput screening investigation. Salinomycin was the most effective agent at destroying CSCs out of a total of 16,000 compounds (7). Salinomycin is a 751 Dalton monocarboxylic polyether antibiotic, which is isolated from the bacterium Streptomyces albus (8). It has a broad spectrum of bioactivity, including antibacterial, antifungal, antiparasetic, antimalarial and tumor cell cytotoxicity (9). It is widely used in veterinary medicine as an antiprotozoal agent against coccidial parasites. Salinomycin is $>100$-fold more effective than paclitaxel at causing CSC death (7). However, the complex underlying mechanisms involved remain to be fully elucidated. A previous study by Riccioni et al (10) reported that salinomycin acts as a potent inhibitor of p-glycoprotein.

The potential clinical treatment options of salinomycin are restricted by neuronal, muscular and other toxicities (11). The former is mediated by an increased concentration of $\mathrm{Na}^{+}$, which leads to an increase in cytosolic $\mathrm{Ca}^{2+}$ concentration via the $\mathrm{Na}^{+} / \mathrm{Ca}^{2+}$ exchanger $\left(\mathrm{Na}^{+} / \mathrm{Ca}^{2+}-\mathrm{X}\right)$ in the plasma membrane and the mitochondria (11). By inhibiting the mitochondrial $\mathrm{Na}^{+} / \mathrm{Ca}^{2+}-\mathrm{X}$ using the benzodiazepine derivate, CGP37157 (CGP), Boehmerle and Endres (11) demonstrated a significant reduction in salinomycin neuronal toxicity. CGP may offer 
potential as a novel additive in treatment with salinomycin to reduce its toxicity and, thus enable future clinical use. The aim of the present study was to investigate whether CGP also inhibits the tumor toxicity of salinomycin.

\section{Materials and methods}

Culture of the human carcinoma cell line. The FaDu HNSCC cell line (American Type Culture Collection, Manassas, VA, USA), which is derived from a human hypopharyngeal carcinoma, and $\mathrm{HLaC} 79$ clone 1 (C1), a paclitaxel resistant clone, were used in the present study. The $\mathrm{HLaC} 79 \mathrm{C} 1$ was generated in the Department of Otolaryngology, University of Wuerzburg (Wuerzburg, Germany) (12-14). The cells were grown in RPMI-1640 medium (Biochrom AG, Berlin, Germany), supplemented with $10 \%$ fetal calf serum (Linaris, Wertheim-Bettingen Germany), $100 \mathrm{U} / \mathrm{ml}$ penicillin, $100 \mu \mathrm{g} / \mathrm{ml}$ streptomycin, $1 \%$ sodium pyruvate $(100 \mathrm{mM}$; Biochrom AG) and $1 \%$ non-essential amino acids (100-fold concentration; Biochrom AG), which was termed RPMI-expansion medium (RPMI-EM). The cells were cultured at $37^{\circ} \mathrm{C}$ with $5 \% \mathrm{CO}_{2}$ in culture flasks. The medium was replaced every other day and passaging was performed on reaching $70-80 \%$ confluence by trypsinization ( $0.25 \%$ trypsin; Gibco Life Technologies, Karlsruhe, Germany), washing with phosphate-buffered saline (PBS; Roche Diagnostics GmbH, Mannheim, Germany) and seeding into flasks or treatment wells. The subsequent experiments were performed using cells in the exponential growth phase.

The HNSCC cells were were seeded at a density of $6 \times 10^{3}$ cells/well and incubated for $24 \mathrm{~h}$ at $37^{\circ} \mathrm{C}$. Subsequently, the cells were treated either with salinomycin $(1,5$ and $10 \mu \mathrm{M}$; Sigma-Aldrich, Schnelldorf, Germany) or with salinomycin (1, 5 and $10 \mu \mathrm{M})+$ CGP $(10 \mu \mathrm{M}$; Sigma-Aldrich) for $24 \mathrm{~h}$, in order to assess the possible interaction between salinomycin and CGP. All experiments were performed in triplicate.

Cell morphology and fluorescein diacetate assay (FDA). The cells were cultured as a monolayer and in three-dimensional conditions (spheroids). Following the treatment with salinomycin, an FDA ( $5 \mathrm{mg} / \mathrm{ml}$ FDA in acetone; Sigma-Aldrich) was used in order to identify viable cells in the culture. Following treatment with salinomycin and salinomycin + CGP for $24 \mathrm{~h}$, the cells $\left(6 \times 10^{3}\right)$ were stained with a solution of $80 \mu \mathrm{g} / \mathrm{ml}$ fluorescein diacetate and $50 \mu \mathrm{g} / \mathrm{ml}$ ethidium bromide (Sigma-Aldrich). Subsequently, the cells were observed under a fluorescence microscope (Leica DMI 4000B Inverted Microscope; Leica Microsystems, Wetzlar, Germany). Living cells convert the non-fluorescent FDA into the green fluorescent compound, fluorescein, while dead cells exhibit red-orange staining in their nuclei.

\section{3-(4,5-dimethylthiazol-2-yl)-2,5-diphenyl tetrazolium} bromide (MTT) assay and clonogenic assay. The MTT assay (Sigma-Aldrich) is a colorimetric staining method, according to Mosmann (15) and was used to study the viability of cells. The plates were incubated with $100 \mu \mathrm{l} \mathrm{MTT}(1 \mathrm{mg} / \mathrm{ml})$, followed by $5 \mathrm{~h}$ incubation at $37^{\circ} \mathrm{C}$ with $5 \% \mathrm{CO}_{2}$. Following the removal of MTT, $100 \mu \mathrm{l}$ isopropanol (Sigma-Aldrich) was added for $1 \mathrm{~h}$ at $37^{\circ} \mathrm{C}$ with $5 \% \mathrm{CO}_{2}$. The viability of the cells was quantified by measuring the absorbance at $570 \mathrm{~nm}$ (Titertek Multiskan PLUS (MK II) ELISA-reader; Labsystems, Helsinki, Finland).

To determine the long-term effects of the treatment reagents, the cells were treated with salinomycin for $24 \mathrm{~h}$ at $37^{\circ} \mathrm{C}$. Subsequently, the supernatant was removed and fresh medium was added. Following incubation for 14 days at $37^{\circ} \mathrm{C}$ the cell colonies were stained with crystal violet (0.4 g/l; Sigma-Aldrich) and counted using the Leica DMI 4000B Inverted Microscope (Leica Microsystems, Wetzlar, Germany).

Annexin V-propidium iodide (PI) staining. Apoptosis of the FaDu and HLaC79 C1 HNSCC cell lines was assessed using an Apoptosis Detection kit (BD Biosciences, Heidelberg, Germany). Following exposure to salinomycin or salinomycin + CGP for $24 \mathrm{~h}$ at different concentrations (1, 5 and $10 \mu \mathrm{M})$ at $37^{\circ} \mathrm{C}$, the cells in suspension and the adherent cells were harvested and washed twice with cold PBS. The cells were resuspended in 1:10 binding buffer (Sigma-Aldrich), containing 0.1 M HEPES ( $\mathrm{pH} 7.4$ ), $1.4 \mathrm{M} \mathrm{NaCl}$ and $25 \mathrm{mM} \mathrm{CaCl}_{2}$, at a concentration of $1 \times 10^{6}$ cells $/ \mathrm{ml}$, and $100 \mu \mathrm{l}$ aliquots of this cell suspension $\left(1 \times 10^{5}\right.$ cells) were subsequently transferred to a $5 \mathrm{ml}$ culture tube. Annexin V-APC $(5 \mu 1)$ and PI $(5 \mu 1)$ were added to each aliquot containing $1 \times 10^{5}$ cells. Following incubation for $15 \mathrm{~min}$ in the dark at room temperature, the cells were resuspended in $400 \mu 1$ 1:10 binding buffer. A FACSCanto flow cytometer (Beckton Dickinson, Heidelberg, Germany) was used to analyze the samples. PI staining is visible in cells with damaged membranes, as observed during necrosis.

Total RNA extraction, and reverse transcription-quantitative polymerase chain reaction ( $R T-q P C R)$. The expression levels of MDR-1 in the FaDu and HLaC79 C1 cells were investigated using RT-qPCR. The total RNA was extracted from the cells using TRIzol reagent (Invitrogen Life Technologies, Carlsbad, CA, USA), according to the manufacturer's instructions. The extracted total RNA was reverse transcribed into cDNA using the High-Capacity RNA-to-cDNA Master Mix (Applied Biosystems, Foster City, CA, USA). For the quantification of gene expression, a SYBR Green PCR Master Mix kit (Applied Biosystems) was used. The MDR-1 primer was purchased from Applied Biosystems, with the following sequences: Forward 5'-AGAAAGCGAAGCAGTGGT TCA-3' and reverse 5'-CGAACTGTAGACAAACGATGAG CTA-3'. PCR was performed in duplicate using $100 \mathrm{ng}$ cDNA per replicate on the StepOnePlus Real-Time PCR system (Applied Biosystems). The amplifications for gene quantification were as follows: $50^{\circ} \mathrm{C}$ for $2 \mathrm{~min}, 95^{\circ} \mathrm{C}$ for $10 \mathrm{~min}$ and 40 cycles of $95^{\circ} \mathrm{C}$ for $15 \mathrm{sec}$ and $60^{\circ} \mathrm{C}$ for $1 \mathrm{~min}$. RNA levels were quantified using a photometer (BioPhotometer; Eppendorf, Hamburg Germany) and the expression levels of GAPDH were used as an internal control.

Statistical analysis. All data were analyzed by statistical analysis with GraphPad Prism software, version 4.0 (GraphPad Software, Inc., La Jolla, CA, USA). To investigate whether the cytotoxic effect of salinomycin was dose-dependent, Friedman's test was used. The Kruskal-Wallis test was conducted for all other tests to evaluate statistical significance. 


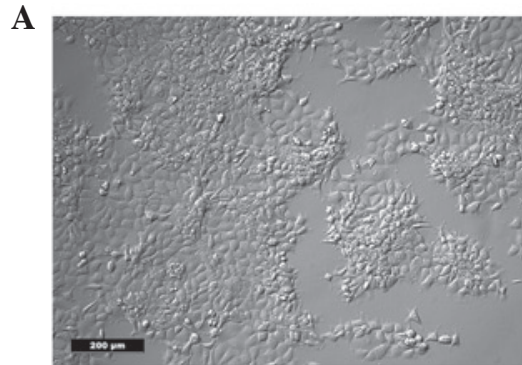

D

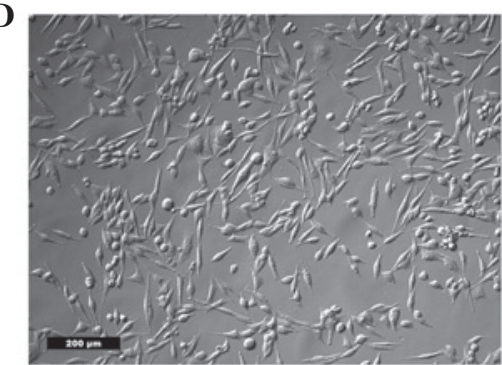

B

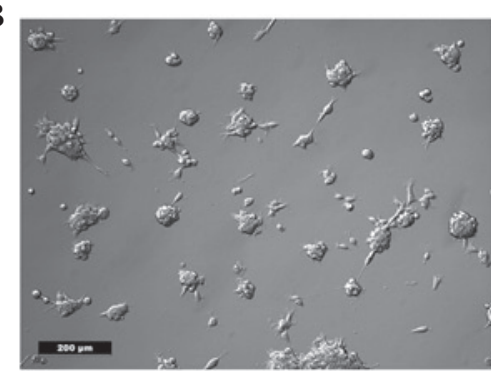

$\mathbf{E}$

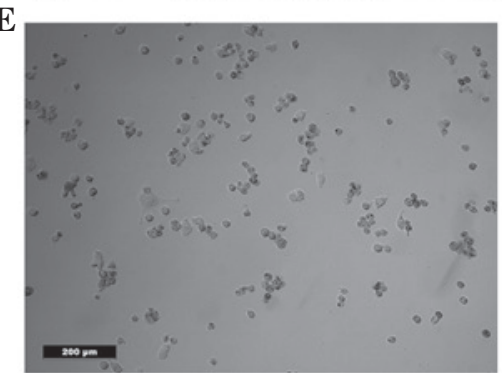

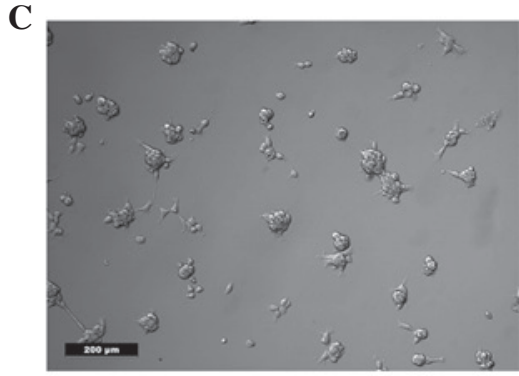

F

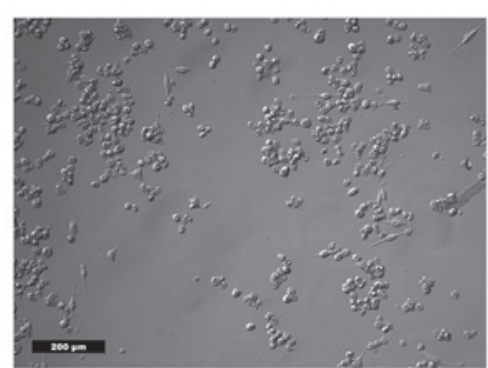

Figure 1. Microscopic analysis of head and neck squamous cell carcinoma cell lines treated with salinomycin or with salinomycin \pm CGP. Representative images of FaDu cells cultivated with (A) RPMI-EM, (B) $10 \mu \mathrm{M}$ salinomycin and (C) $10 \mu \mathrm{M}$ salinomycin $\pm 10 \mu \mathrm{M}$ CGP. Representative images of HLaC79 C1 cells cultivated with (D) RPMI-EM, (E) $10 \mu \mathrm{M}$ salinomycin and (F) $10 \mu \mathrm{M}$ salinomycin $\pm 10 \mu \mathrm{M}$ CGP. Magnification, x100. Significant attenuation of cell viability was observed following treatment with salinomycin. No differences were demonstrated between the cells treated with salinomycin and the cells treated with salinomycin \pm CGP. CGP, CGP37157; RPMI-EM, RPMI-expansion medium.
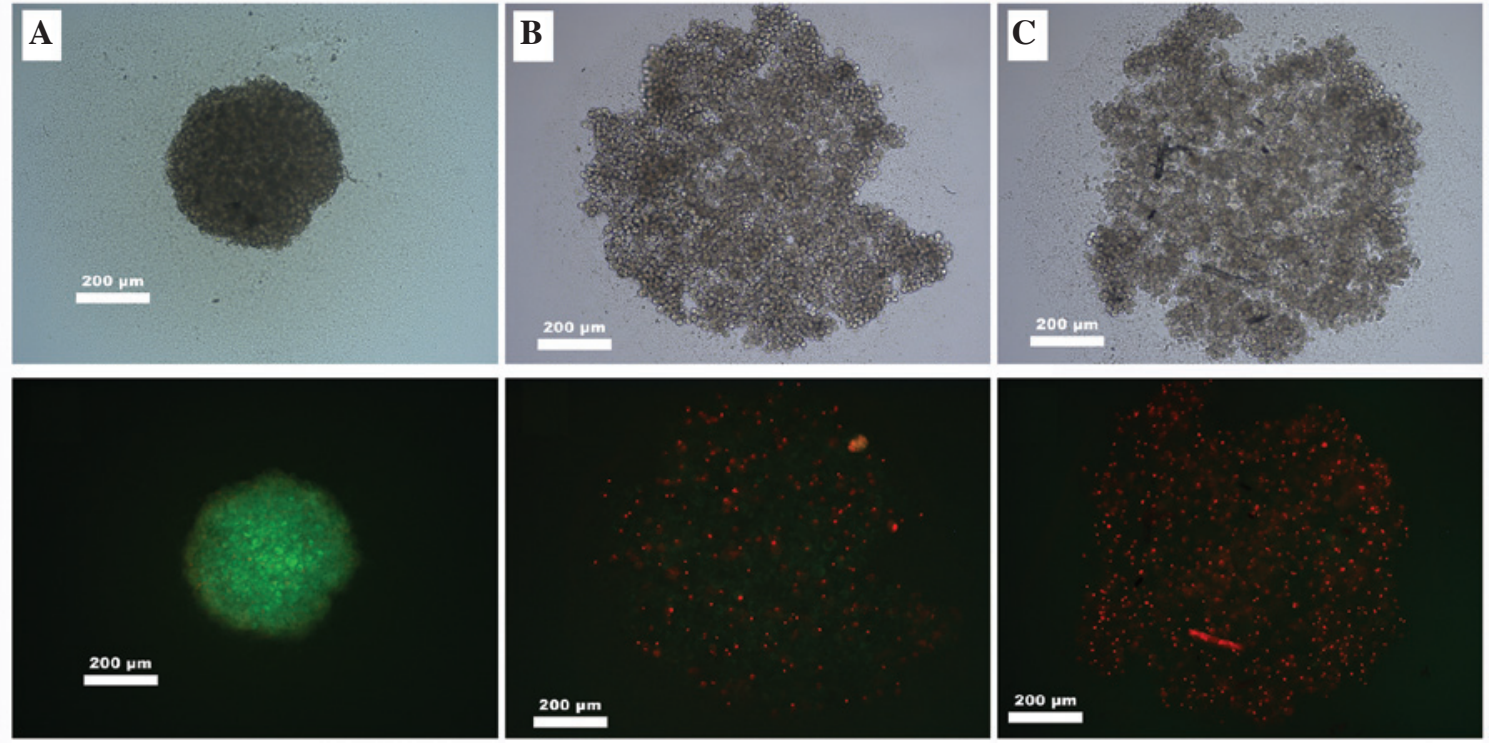

Figure 2. FaDu spheroids were assessed following treatment with salinomycin or salinomycin \pm CGP. Cells cultivated in RPMI-expansion medium were used as a control. A fluorescein diacetate assay was used to identify viable and dead cells. Viable cells retain the ability to convert the non-fluorescent fluorescein diacetate into a green fluorescent composite, wheras red-orange fluorescence is observed in the presence of nuclear membrane damage. (A) Untreated FaDu spheroid of viable cells, determined by green fluorescence. (B) FaDu spheroid treated with $10 \mu \mathrm{M}$ salinomycin for $24 \mathrm{~h}$ and (C) FaDu spheroid treated with $10 \mu \mathrm{M}$ salinomycin \pm CGP for $24 \mathrm{~h}$ exhibited dead cells, indicated by a red-orange appearance. The images are representative of the phase contrast (top row) and fluorescencent microscopy (bottom row) images. CGP, CGP37157.

$\mathrm{P}<0.05$ was considered to indicate a statistically significant difference.

\section{Results}

Cell morphology and FDA. Following treatment with salinomycin or salinomycin + CGP, the morphology of the FaDu and HLaC79 C1 cells was assessed using an inverted microscope. No morphological differences were observed between the cells treated with salinomycin and the cells treated with salinomycin + CGP (Fig. 1). In each group, the cells were rounded, suggesting they were undergoing apoptosis.

Following spheroid formation, the cells were treated with salinomycin or salinomycin + CGP. The cells were then stained with FDA solution. A significant attenuation of cell viability was observed following the FDA staining, with no weakening of salinomycin tumor toxicity caused by the addition of CGP (Fig. 2). 
A

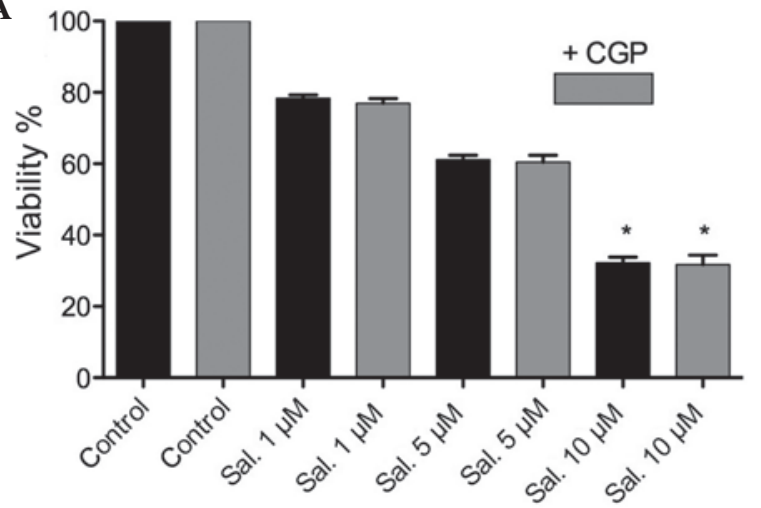

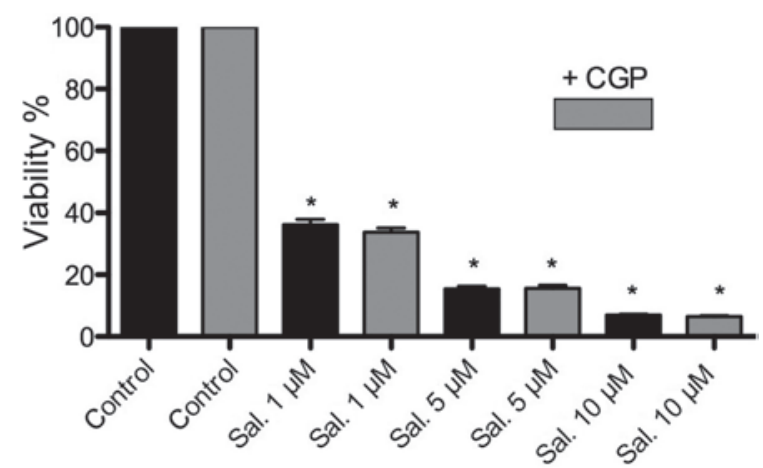

Figure 3. MTT assay of head and neck squamous cell carcinoma cell lines under different treatment conditions. The cells were treated with different concentrations of Sal or Sal $+10 \mu \mathrm{M}$ CGP for $24 \mathrm{~h}$. Following treatment for $24 \mathrm{~h}$ an MTT assay was performed, which revelaed a significant attenuation of cell viability, in a dose-dependent manner. (A) FaDu cells exhibited a significant reduction in cell viability following treatment with $10 \mu \mathrm{M} \mathrm{Sal}$. (B) HLaC79 C1 cells exhibited a significant attenuation in cell viability following treatment with $1 \mu \mathrm{M}$ Sal. No inhibition of Sal tumor toxicity was observed following the addition of CGP. "P<0.05 vs. control. Data are expressed as the mean \pm standard deviation of triplicate measurements. MTT, 3-(4,5-dimethylthiazol-2-yl)-2,5-diphenyl tetrazolium bromide; Sal, salinomycin; CGP, CGP37157.
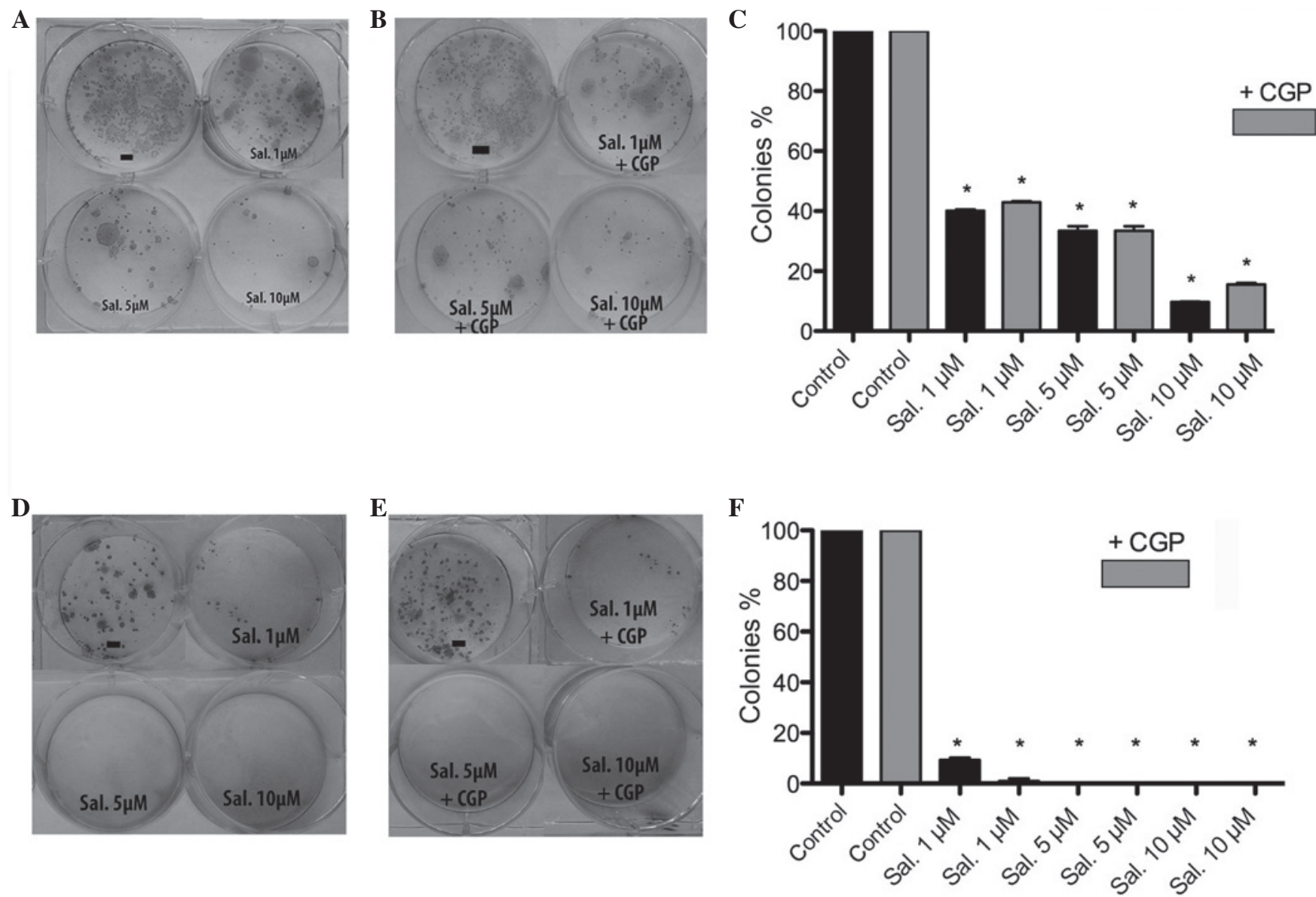

Figure 4. Colony assay of head and neck squamous cell carcinoma cell lines under different treatment conditions. The cells were treated with increasing concentrations of Sal or Sal $\pm 10 \mu \mathrm{M}$ CGP for $24 \mathrm{~h}$. Following treatment for $24 \mathrm{~h}$, the medium was replaced. The cells were cultured for 14 days, following which the cell colonies were stained with crystal violet. The (A-C) FaDu and (D-F) HLaC79 C1 cells exhibited a significant reduction in colony formation. No inhibition of salinomycin tumor toxicity was observed following the addition of CGP. ${ }^{*} \mathrm{P}<0.05$ vs. control. Data are expressed as the mean \pm standard deviation of triplicate measurements. Sal, salinomycin; CGP, CGP37157; -, untreated control.

MTT assay and clonogenic assay. Following treatment with salinomycin or salinomycin + CGP, an MTT assay was performed. A significant $(\mathrm{P}<0.05)$ dose-dependent attenuation of cell viability was observed following treatment with salinomycin. The combination of salinomycin and CGP revealed no inhibition of salinomycin tumor toxicity. However, a significant difference between the FaDu and HLaC79 C1 cells was observed in terms of the concentra- 
A

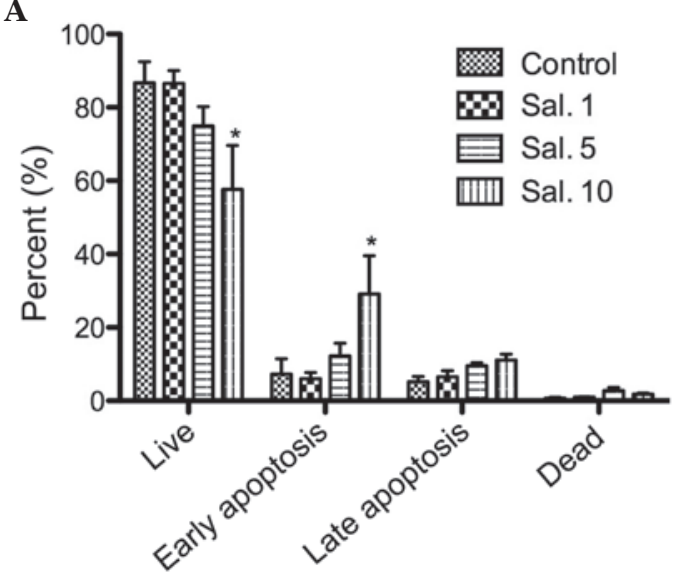

C

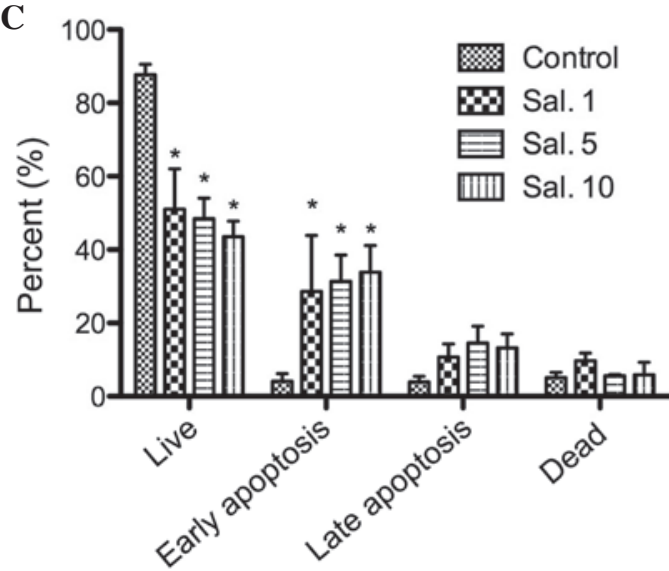

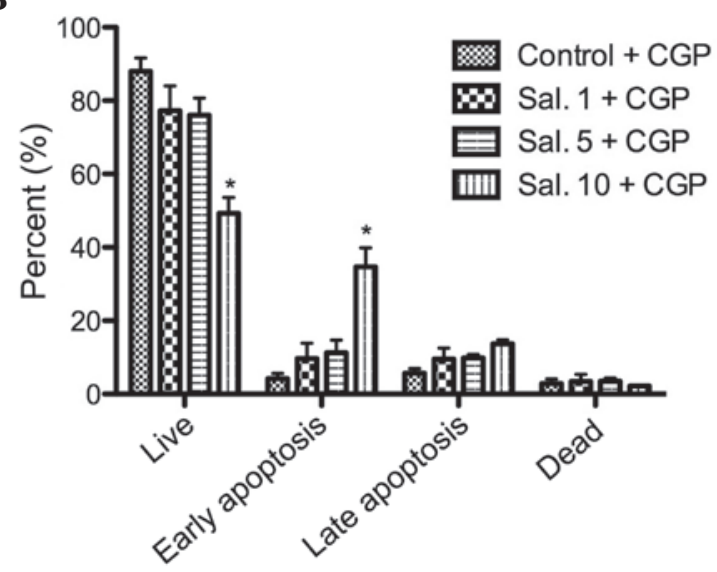

D

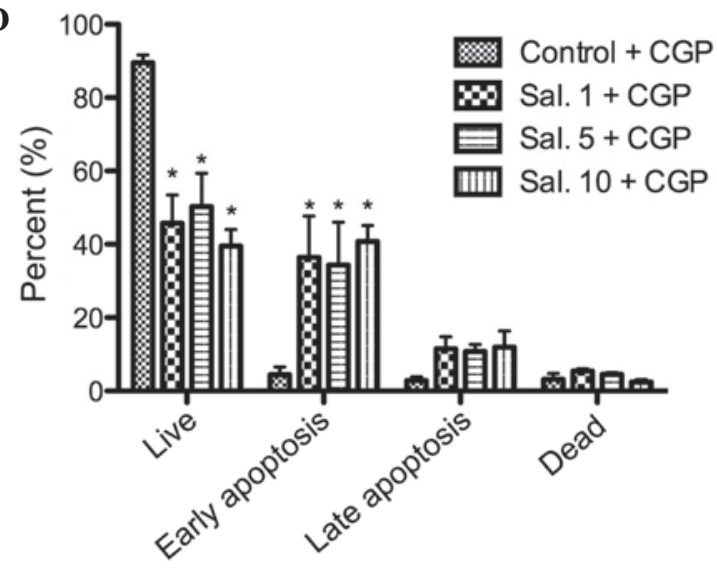

Figure 5. Annexin V-PI assay of apoptosis. The results of annexin V-PI staining revealed a dose-dependent increase of early apoptosis following treatment of the (A) FaDu cells with Sal. Following the addition of (B) CGP, the tumor toxicity of Sal was not counteracted. The increase of HLaC79 C1 apoptosis following treatment with (C) Sal or (D) Sal + CGP. No significant increases in late apoptosis or cell necrosis were observed following treatment with Sal at high concentrations. ${ }^{*} \mathrm{P}<0.05$ vs. control. Data are expressed as the mean \pm standard deviation of triplicate measurements. Sal, salinomycin; CGP, CGP37157; PI, propidium iodide.

tion of salinomycin $(\mathrm{P}<0.05)$. The half maximal inhibitory concentration $\left(\mathrm{IC}_{50}\right)$ of salinomycin in the $\mathrm{FaDu}$ cells was calculated to be between 5 and $10 \mu \mathrm{M}$, whereas the $\mathrm{IC}_{50}$ of the HLaC79 C1 cells was calculated to be between 0.5 and $1 \mu \mathrm{M}$. The MTT assay revealed no counteraction of salinomycin tumor toxicity following the addition of CGP. Assessment of colony formation revealed the inhibition of colony formation following treatment with salinomycin, which was not inhibited by the addition of CGP. The HLaC79 C1 cells reacted more sensitively to salinomycin, compared with the $\mathrm{FaDu}$ cells (Figs. 3 and 4).

Annexin V-PI staining. The annexin V-PI staining was performed to confirm the results of the MTT assay and to differentiate between cell apoptosis and cell necrosis. No increase in the number of apoptotic cells was observed following treatment with CGP. A dose-dependent cell apoptosis response was observed following treatment with salinomycin. The HLaC79 C1 cells were more sensitive to salinomycin, compared with the FaDu cells (Fig. 5). The rate of early apoptosis increased significantly $(\mathrm{P}<0.05)$ in a dose-dependent manner in the FaDu cells. No improvements in the rates of late apoptosis and necrosis were observed as the concentration of salinomycin increased (Fig. 5). The

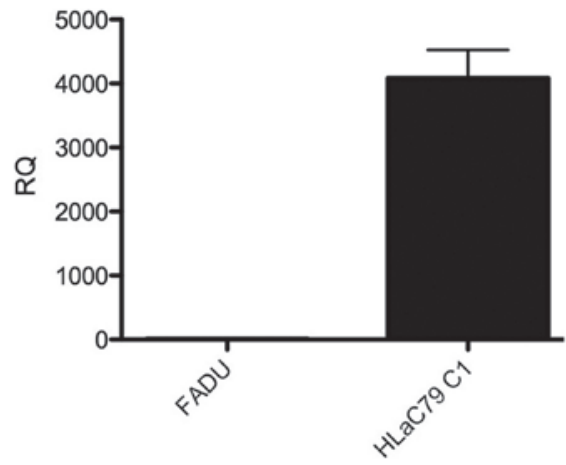

Figure 6. Expression levels of MDR-1 were assessed using reverse transcription-quantitative polymerase chain reaction. The HLaC79 $\mathrm{C} 1$ cells exhibited high expression levels of MDR-1, whereas no MDR-1 was expressed in the FaDu cells. Data are expressed as the mean \pm standard deviation of triplicate measurements. RQ, relative quantity.

addition of CGP did not counteract the tumor toxicity of salinomycin (data not shown).

$R T-q P C R$. The expression levels of MDR-1 in the FaDu and HLaC79 C1 cancer cell lines were assessed using RT-qPCR. The HLaC79 C1 cell line was observed to exhibit positive 
expression of MDR-1, however no expression of MDR-1 was detected in the FaDu cells (Fig. 6).

\section{Discussion}

The antitumor activity of salinomycin has been demonstrated in different types of CSCs, including breast CSCs (7), leukemia stem cells (16) and pancreatic CSCs (17). The mechanisms involved in tsalinomycin-induced cancer stem cell death remain to be fully elucidated. Lu et al (18) identified salinomycin as an inhibitor of the Wnt $/ \beta$-catenin signaling pathway. Salinomycin also inhibits the phosphorylation of Wnt-induced lipoprotein receptor related protein 6 (LRP6). This causes degradation of LRP6 and leads to the apoptosis of CSCs (18). In a previous study, Arafat et al (19) demonstrated that salinomycin caused concentration- and time-dependent reductions in the viability of HNSCC cell lines through a caspase 3/7-associated cell death pathway (19). In the present study, salinomycin induced dose-dependent apoptosis in the HNSCC cells. The sensitivities of the two cell lines differed significantly, with the $\mathrm{HLaC} 79 \mathrm{C} 1$ cells being more sensitive to salinomycin, compared with the $\mathrm{FaDu}$ cells. At a concentration of $1 \mu \mathrm{M}$, cell death was observed in $\sim 60 \%$ of the HLaC79 C1 cells, which is a salinomycin concentration $\sim 10$ times lower than the concentration required to achieve the same effect in the FaDu cells. The divergence in sensitivity between each cell line was also demonstrated in the annexin and colony assays. Following the addition of CGP, no alterations in salinomycin tumor toxicity were observed. One reason may be due to the expression of an MDR-1 receptor. Riccioni et al (10) demonstrated that salinomycin acted as a potent inhibitor of MDR-1. This was achieved through a conformational change in the adenosine triphosphate transporter (10). The present study revealed, using RT-qPCR, that MDR-1 was highly expressed in the $\mathrm{HLaC} 79 \mathrm{C} 1$ cells.

Overexpression of MDR-1 in cancer cells is associated with a poor clinical outcome due to its resistance to a majority of the drugs used (20), therefore, salinomycin may be a promising candidate in these cases. The major obstacle to using salinomycin is its cytotoxicity. The mechanism of salinomycin in dealing with rumen microflora and coccidia is well known (21), however, the toxic effect in mammals remains to be fully elucidated. Notably, the toxic effects of salinomycin depend on the species, for example, it exhibits low toxicity in poultry and cattle, and high toxicity in horses and dogs (9). Although the available data on the toxicity of salinomycin in humans is limited, there is one case report on human poisoning by salinomycin (22). In this case, a farmer accidently ingested salinomycin at an unknown concentration, which resulted in life-threatening neuropathia, rhabdomyolysis and hospitalization for 6 weeks. The concentration of salinomycin in the plasma remained undetermined, however, it was estimated that $1 \mathrm{mg} / \mathrm{kg}$ body weight was ingested. In our previous study (23), the effects of salinomycin on human mesenchymal stem cells (hMSCs) was investigated. The essential functional properties of hMSC were unaffected by treatment with salinomycin, however, dose-dependent cytotoxicity effects were observed (23). Minati et al (24) examined the effects of salinomycin on alkali cation transport and membrane functions in rat liver mitochondria, the results of which demonstrated that salinomycin inhibits mitochondrial functions by acting as a mobile carrier for alkali cations through membranes (24). Boehmerle and Endres (11) reported that salinomycin neuronal toxicity is mediated by an increase in the concentration of $\mathrm{Na}^{+}$, which causes an increase in cytosolic $\mathrm{Ca}^{2+}$ concentration via $\mathrm{Na}^{+} / \mathrm{Ca}^{2+}-\mathrm{X}$ in the plasma membrane and mitochondria (11). This effect was significantly inhibited following the addition of the CGP benzodiazepine derivate.

Additives in tumor therapy are required to reduce the toxicity of anticancer drugs. Human serum albumin-thioredoxin-1 has been used as an effective additive for preventing cisplatin nephrotoxicity (25). Kojouharov et al (26) demonstrated the reduction of 5-fluorouracil (5-FU) toxicity by the toll-like receptor 5 (TLR5) agonist, entolimod, in an in vivo model. TLR5 did not reduce the antitumor efficacy of 5-FU, however, the major potential concern of using entolimod was its protective/regenerative effects, which potentially reduced the antitumor efficacy of the chemotherapy (26). The most important fact for additives in tumor therapy is that they do not interact with the anticancer drug. In the present study, CGP did not counteract the tumor toxicity of salinomycin, nor did it exhibit any antitumor activity.

In conclusion, salinomycin may be a promising drug in future anticancer therapy, with CGP as a potential additive to reduce its toxicity. However, further investigations are required to examine the toxicological aspects of salinomycin in human cells. Healthy organs, which express MDR-1, including the liver, kidney, small intestine and colon, may be highly sensitive to salinomycin. Therefore, toxicological investigations of healthy cells, healthy cells expressing MDR-1, and animal experiments are required to identify critical organs in salinomycin treatment.

\section{Acknowledgements}

This study was supported by the Rudolf Bartling Stiftung (Rudolf Bartling Foundation), Hannover, Germany (grant no. II/92/2006).

\section{References}

1. Parkin DM, Bray F, Ferlay J and Pisani P: Global cancer statistics, 2002. CA Cancer J Clin 55: 74-108, 2005.

2. Seiwert TY and Cohen EE: State-of-the-art management of locally advanced head and neck cancer. Br J Cancer 92: 1341-1348, 2005.

3. Vermorken JB, Remenar E, van Herpen C, Gorlia T, Mesia R, Degardin M, Stewart JS, Jelic S, Betka J, Preiss JH, et al; EORTC 24971/TAX 323 Study Group: Cisplatin, fluorouracil, and docetaxel in unresectable head and neck cancer. N Engl J Med 357: 1695-1704, 2007.

4. Prestwich RJ, Öksüz DÇ, Dyker K, Coyle C and Şen M: Feasibility and efficacy of induction docetaxel, cisplatin, and 5-fluorouracil chemotherapy combined with cisplatin concurrent chemoradiotherapy for nonmetastatic Stage IV head-and-neck squamous cell carcinomas. Int J Radiat Oncol Biol Phys 81: e237-e243, 2011.

5. Boman BM and Wicha MS: Cancer stem cells: A step toward the cure. J Clin Oncol 26: 2795-2799, 2008.

6. Davis SJ, Divi V, Owen JH, Bradford CR, Carey TE, Papagerakis S and Prince ME: Metastatic potential of cancer stem cells in head and neck squamous cell carcinoma. Arch Otolaryngol Head Neck Surg 136: 1260-1266, 2010.

7. Gupta PB, Onder TT, Jiang G, Tao K, Kuperwasser C, Weinberg RA and Lander ES: Identification of selective inhibitors of cancer stem cells by high-throughput screening. Cell 138: 645-659, 2009. 
8. Mitani M, Yamanishi T and Miyazaki Y: Salinomycin: A new monovalent cation ionophore. Biochem Biophys Res Commun 66 1231-1236, 1975.

9. Huczynski A: Salinomycin: A new cancer drug candidate. Chem Biol Drug Des 79: 235-238, 2012.

10. Riccioni R, Dupuis ML, Bernabei M, Petrucci E, Pasquini L, Mariani G, Cianfriglia M and Testa U: The cancer stem cell selective inhibitor salinomycin is a p-glycoprotein inhibitor. Blood Cells Mol Dis 45: 86-92, 2010.

11. Boehmerle W and Endres M: Salinomycin induces calpain and cytochrome c-mediated neuronal cell death. Cell Death Dis 2: e168, 2011.

12. Rangan SR: A new human cell line $(\mathrm{FaDu})$ from a hypopharyngeal carcinoma. Cancer 29: 117-121, 1972.

13. Schmidt M, Polednik C, Gruensfelder P, Roller J and Hagen R: The effects of PC-Spes on chemosensitive and chemoresistant head and neck cancer cells and primary mucosal keratinocytes. Oncol Rep 21: 1297-1305, 2009.

14. Zenner HP, Lehner W and Herrmann IF: Establishment of carcinoma cell lines from larynx and submandibular gland. Arch Otorhinolaryngol 225: 269-277, 1979.

15. Mosmann T: Rapid colorimetric assay for cellular growth and survival: Application to proliferation and cytotoxicity assays. J Immunol Methods 65: 55-63, 1983.

16. Fuchs D, Heinold A, Opelz G, Daniel V and Naujokat C: Salinomycin induces apoptosis and overcomes apoptosis resistance in human cancer cells. Biochem Biophys Res Commun 390: 743-749, 2009.

17. Zhang GN, Liang Y, Zhou LJ, Chen SP, Chen G, Zhang TP, Kang T and Zhao YP: Combination of salinomycin and gemcitabine eliminates pancreatic cancer cells. Cancer Lett 313: 137-144, 2011

18. Lu D, Choi MY, Yu J, Castro JE, Kipps TJ and Carson DA Salinomycin inhibits Wnt signaling and selectively induces apoptosis in chronic lymphocytic leukemia cells. Proc Natl Acad Sci USA 108: 13253-13257, 2011.
19. Arafat K, Iratni R, Takahashi T, Parekh K, Al Dhaheri Y, Adrian TE and Attoub S: Inhibitory Effects of Salinomycin on Cell Survival, Colony Growth, Migration, and Invasion of Human Non-Small Cell Lung Cancer A549 and LNM35: Involvement of NAG-1. PLoS One 8: e66931, 2013.

20. Szakács G, Paterson JK, Ludwig JA, Booth-Genthe C and Gottesman MM: Targeting multidrug resistance in cancer. Nat Rev Drug Discov 5: 219-234, 2006.

21. Zhou S, Wang F, Wong ET, Fonkem E, Hsieh TC, Wu JM and Wu E: Salinomycin: A novel anti-cancer agent with known anti-coccidial activities. Curr Med Chem 20: 4095-4101, 2013.

22. Story P and Doube A: A case of human poisoning by salinomycin, an agricultural antibiotic. N Z Med J 117: U799, 2004.

23. Scherzed A, Hackenberg S, Froelich K, Rak K, Technau A, Radeloff A, Nöth U, Koehler C, Hagen R and Kleinsasser N: Effects of salinomycin on human bone marrow-derived mesenchymal stem cells in vitro. Toxicol Lett 218: 207-214, 2013.

24. Mitani M, Yamanishi T, Miyazaki Y and Otake N: Salinomycin effects on mitochondrial ion translocation and respiration. Antimicrob Agents Chemother 9: 655-660, 1976.

25. Kodama A, Watanabe H, Tanaka R, Kondo M, Chuang VT, Wu Q, Endo M, Ishima Y, Fukagawa M, Otagiri M, et al: Albumin fusion renders thioredoxin an effective anti-oxidative and anti-inflammatory agent for preventing cisplatin-induced nephrotoxicity. Biochim Biophys Acta 1840: 1152-1162, 2014

26. Kojouharov BM, Brackett CM, Veith JM, Johnson CP, Gitlin II, Toshkov IA, Gleiberman AS, Gudkov AV and Burdelya LG: Toll-like receptor-5 agonist Entolimod broadens the therapeutic window of 5 -fluorouracil by reducing its toxicity to normal tissues in mice. Oncotarget 5: 802-814, 2014. 